$\Phi=$ 잘

\title{
Assessment and comparison of the levels of N-nitrosonornicotine and 4-(n-methyl-n -nitrosamino) -1-(3-pyridyl)-1-butanone in the saliva of tobacco chewers and non- chewers -a hospital based study
}

\author{
Dr. Harpreet Kaur Gandhoke ${ }^{1}$, Dr. Vasanti Lagali Jirge ${ }^{2}$, Dr. Anjana Bagewadi ${ }^{3}$ \\ ${ }^{1}$ Postgraduate Student, Department of Oral Medicine and Radiology, KAHER'S KLEVKIDS JNMC Campus, \\ Nehru Nagar Belagavi, Karnataka \\ ${ }^{2}$ Reader, Department of Oral Medicine and Radiology, KAHER'S KLEVKIDS JNMC Campus, Nehru Nagar Belagavi, Karnataka \\ ${ }^{3}$ Professor and Head, Department of Oral Medicine and Radiology, KAHER'S KLEVKIDS JNMC Campus, \\ Nehru Nagar Belagavi, Karnataka \\ *Corresponding author E-mail: kaurharpreet1336@gmail.com
}

\begin{abstract}
Background: Studies estimating the Tobacco- specific nitrosamines, (TSNA's) which are the strongest carcinogens in the saliva of tobacco users and tobacco quitters, are limited.

Objectives: To assess and compare the levels of N- nitrosamines (NNN, NNK) in the saliva of tobacco chewers and non -chewers including those who have quit the habit of tobacco use.

Methods: The study included 120 patients who were divided into three groups of 40 each: Group I- Smokeless tobacco chewers

Group II- Tobacco chewers who have completely stopped the habit at least 2 weeks prior to sample collection and

Group III- non-chewers. The salivary levels of two tobacco specific nitrosamines; NNN \& NNK levels were estimated in the three study groups. Statistical analysis was done by Kruskal- Wallis, one-way analysis of variance (ANOVA) test, Mann-Whitney U test. (p-value < 0.05 was considered to be statistically significant)

Results: In Group I, the mean level of NNN was $651.84 \pm 359.78$ and mean level of NNK was $168.32 \pm 131.83$. In Group II, the mean level of NNN was $119.52 \pm 95.05$ and mean level of NNK was $42.78 \pm 43.19$. In Group III, the mean level of NNN was $3.44 \pm 6.55$ and mean level of NNK was $1.98 \pm 3.68$. There was a statistical difference in the 3 groups with respect to mean levels of NNN and NNK.

Conclusion: The study indicated that salivary tobacco-specific nitrosamines are elevated in tobacco chewers. Saliva can be used to detect TSNA's and screen for TSNA's during each patient's de-addiction process.
\end{abstract}

Keywords: NNK; NNN; Saliva; Smokeless Tobacco; Tobacco-Specific Nitrosamines (TSNA's).

\section{Introduction}

The use of tobacco is one of the greatest threats to health worldwide today. Since pre-historic times, tobacco and betel nut chewing habits have existed. Tobacco-specific nitrosamines (TSNA's) are the most prevalent strong carcinogens in smokeless tobacco products and are widely believed to play a causative role in the occurrence of oral cancer in people who use these products. (GTAS 2009-2010) Studies have shown that saliva of tobacco chewers contains significant amounts of carcinogenic TSNA's and that their concentrations can vary widely. (Hoffman \& Adams 1981) Therefore this study was an attempt to use saliva to determine and compare exposure to TSNA's (NNN, NNK) in tobacco chewers, non chewers and in persons those who have quit the habit of tobacco use by measuring these compounds in saliva. The aim of the study was to assess and compare the levels of $\mathrm{N}$ nitrosamines (NNN, NNK) in the saliva of tobacco chewers and non- chewers including those who have quit the habit of tobacco use.

\section{Subjects and methods}

\subsection{Source of data}

Patients visiting the Department of Oral Medicine, Diagnosis and Radiology at KAHER's KLE V.K. Institute of Dental Sciences, Belagavi were included in the study after obtaining an informed consent. The study was approved by the Ethical and Research Committee of KAHER's K.L.E. VK Institute of Dental Sciences, Belagavi.

\subsection{Methods of collection of data}

The study included 120 patients which were divided into three groups of 40 each and the sampling method which was implemented was 'Simple random sampling'.

Group I - Tobacco chewers (Persons chewing any smokeless form of tobacco) 
Group II- Tobacco Chewers who had completely quit the habit at least 2 weeks prior to sample collection

Group III -Patients who had no tobacco consumption habit

Patients fulfilling the following criteria were included in the study-

Patients aged 18 years or above who were tobacco chewers with or without gutka chewing, patients who had no tobacco habit and patients who had quit the tobacco habit at least 2 weeks prior to sample collection

The patients who were excluded from the study were those using smoked tobacco products, suffering from salivary gland disorders or taking any medications which compromised salivary gland function and medically compromised patients. The

armamentarium included face mask, gloves, kidney tray, mouth mirror, guaze, tweezer and a sterile container (Fig 1)

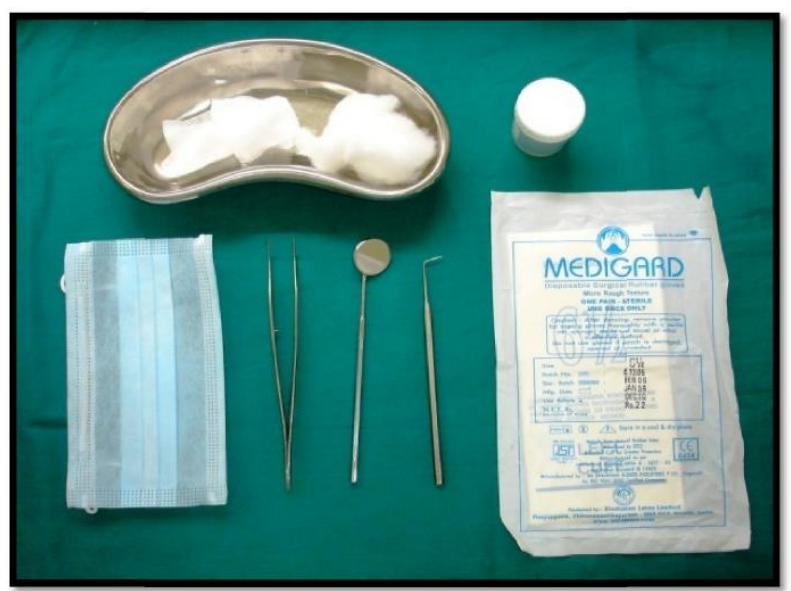

Fig. 1: Armamentarium Used for Clinical Examination and Collection of Saliva.

After obtaining a detailed case history and performing clinical examination, each study subject was explained the details of the study and saliva collection procedure. Informed consent was obtained before obtaining the saliva samples.

\subsection{Collection and storage of saliva samples}

The subjects were asked to refrain from eating and drinking at least one hour prior to giving their saliva samples. They were made to sit comfortably erect in the dental chair and allow the saliva to collect in the floor of mouth for 3-5 minutes and the morning sample was collected. The patient was also enquired about the consumption of any liquid, foodstuffs and alcohol 12 hours prior to sample collection. The samples of whole unstimulated saliva were collected by spitting method. (Fig. 2)

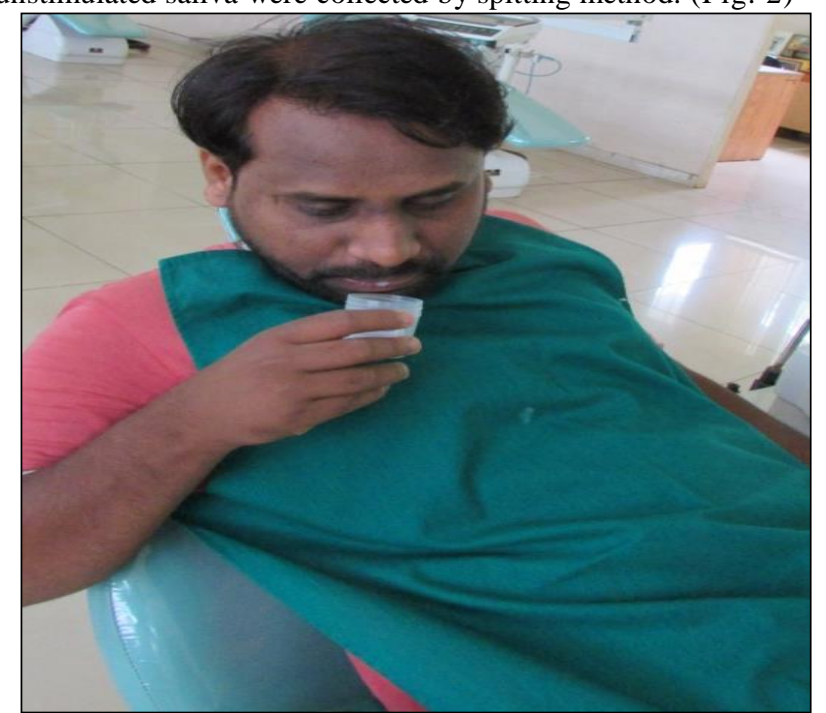

Fig. 2: Collection of Unstimulated Saliva by Saliva Spit Method.
Subjects were made to rinse with a plain glass of water to remove loosely adherent debris from the teeth. Whole unstimulated saliva was collected by asking the patient to spit into a sterile, open mouthed, labeled, plastic container for 10 minutes. The saliva was collected and $2 \mathrm{M}$ sulphamic acid (4 parts saliva: 1 part sulphamic acid) was added to which $1 \mathrm{ml} 10 \mathrm{~N}-\mathrm{NaOH}$ was added as preservative. (Fig. 3)

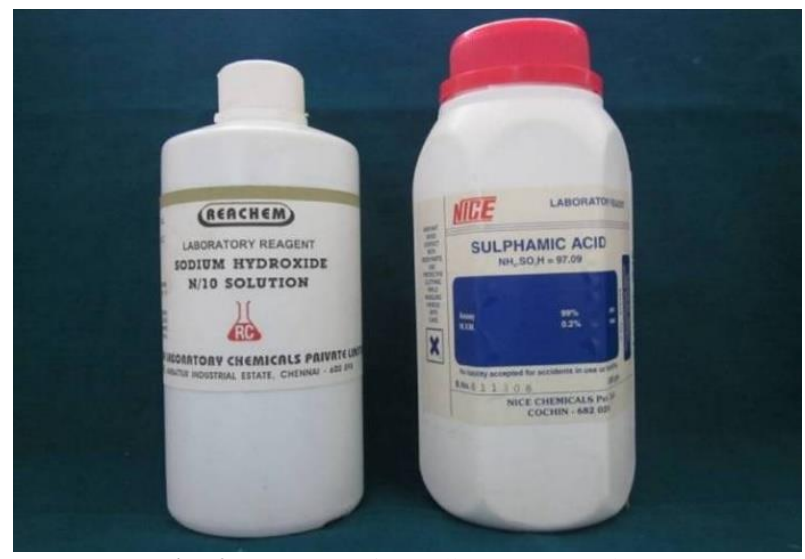

Fig. 3: Reagents for Saliva Preservation.

The samples were then immediately transported on ice packs to the biochemical laboratory at KAHER'S Dr. Prabhakar Kore's Basic Research Centre, Belagavi and stored at $-20^{\circ} \mathrm{C}$ till further analysis.

\subsection{Sample preparation}

One $\mathrm{ml}$ of saliva was taken to which was added $2 \mathrm{ml}$ of Acetonitrile (ACN). (Fig. 4)

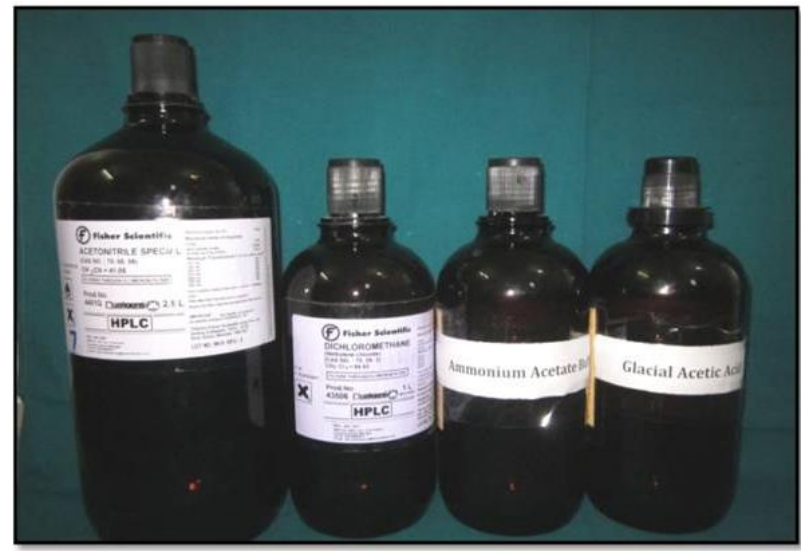

Fig. 4: Reagents Used for Estimation of Nitrosamines by GCMS.

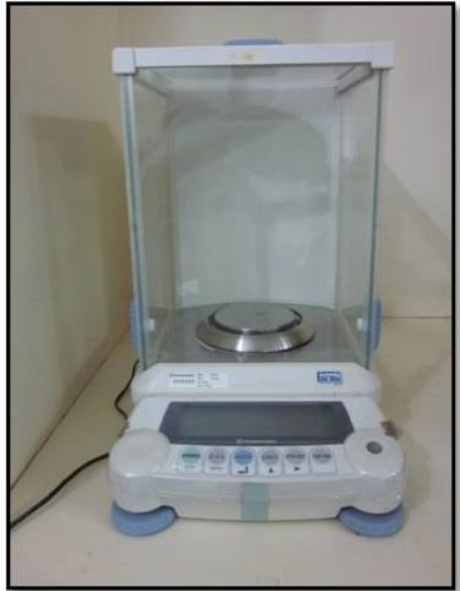

Fig. 5: Precision Scale for Weighing Samples. 


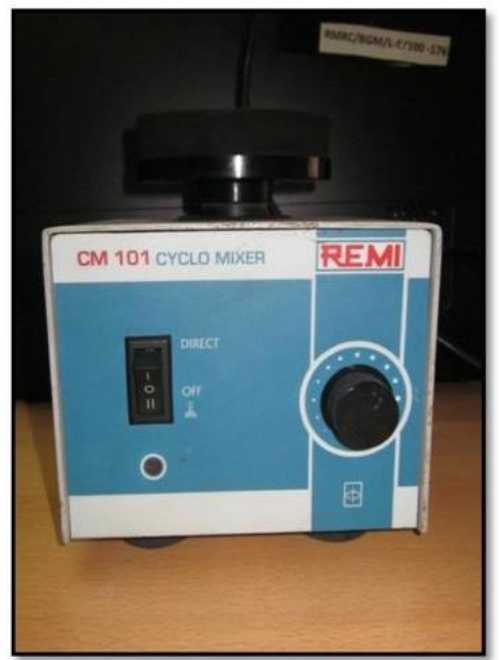

Fig. 6: Cyclomixer for Vortexing.

The mixture was vortexed for 90 seconds. (Fig. 5 and 6)

The solvent was evaporated at room temperature and $500 \mu \mathrm{L}$

of acetonitrile was added before injecting into Gas

chromatography with mass spectrometry (GCMS). (Fig.7).

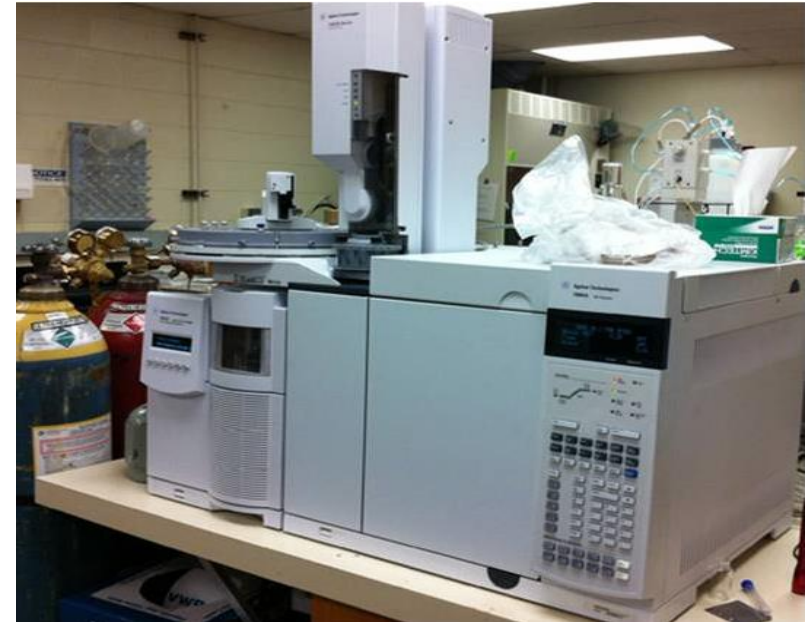

Fig. 7: Gas Chromatography with Mass Spectrometry (GC-MS) - Agilent.

This extraction procedure was carried out at ICMR, Regional Medical Research Centre, Belagavi.

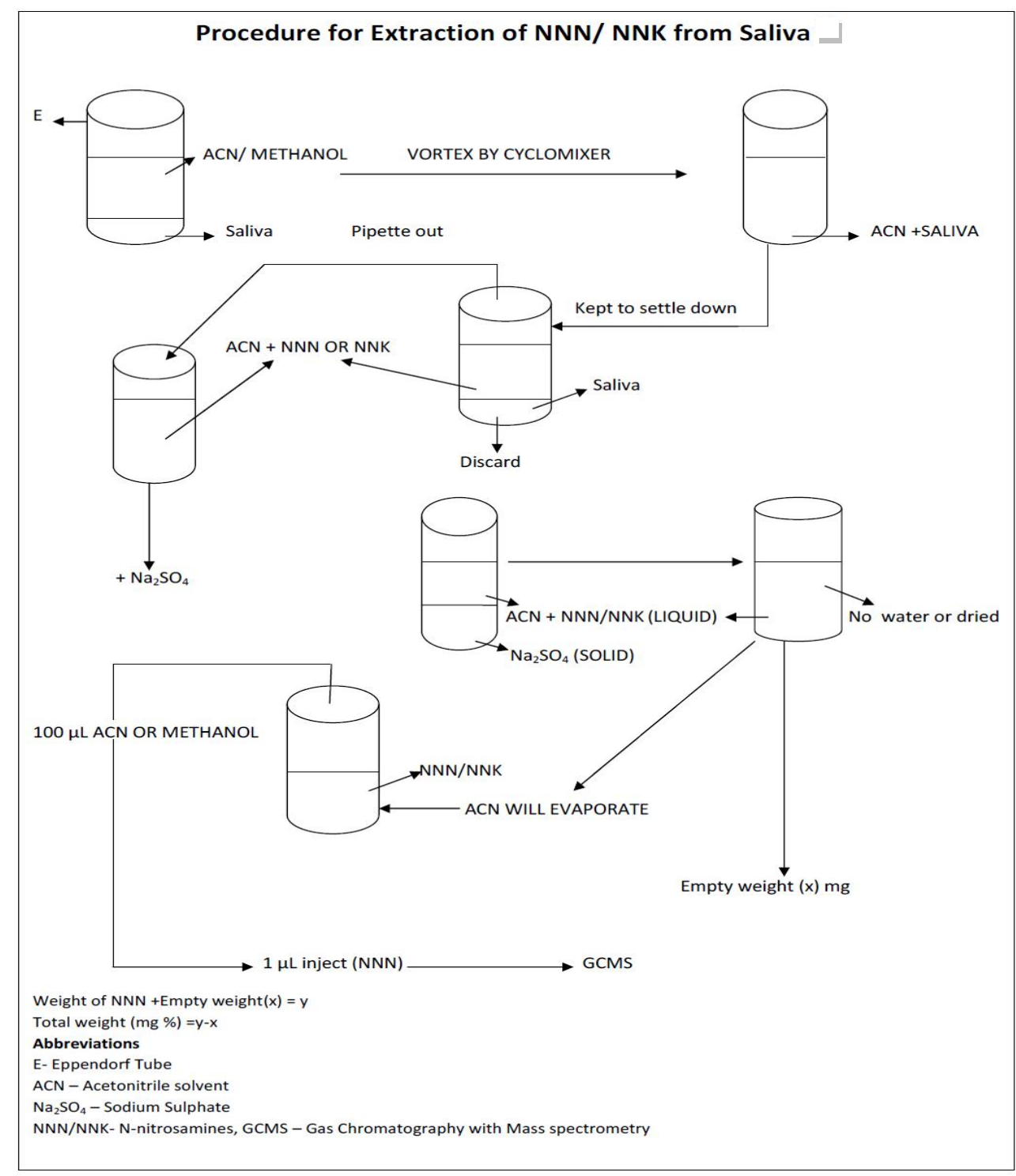

Fig. 8: Procedure for Extraction of NNN/NNK from Saliva (Sugandha, Joshi Et Al. 2015)

Standards for NNK and NNN were obtained from Sigma Aldrich, USA. $10 \mathrm{mg}$ of each was dissolved in $25 \mathrm{ml}$ of ACN to obtain 400ppm of Stock A. The calibration curves for both the standards were established by plotting peak areas, (Area under curve- AUC) against their respective concentrations. The samples were sent on ice packs to Jawaharlal Nehru Centre for Advanced 
Scientific Research, Bangalore (JNCASR) for analysis of NNN and NNK estimation in saliva by Gas Chromatography with Mass Spectrometry (GC-MS) (Pic.7)

\subsection{Quantification of NNN and NNK using GC-MS in- strumentation}

The GC-MS analysis was performed on Agilent chromatographic system consisting of a quaternary pump, manual injector, degasser and dual $\lambda \mathrm{UV}$ absorbance diode array detector. The built in GCMS-solution software system was used for data processing. Chromatographic separation was achieved on a C18 100A phenomenex column (Luna, $5 \mu \mathrm{m}, 4.6 \times 150 \mathrm{~mm}$ ).

\subsection{Chromatographic conditions}

Mobile phase consisting of $\mathrm{ACN}$ in $1 \mathrm{M}$ Ammonium Acetate (NH4OAC) buffer, water with glacial acetic acid and ACN was used for separation (70:20:10) in low pressure gradient mode with injection volume $20 \mu \mathrm{L}$.

Flow rate $0.4 \mathrm{~mL} / \mathrm{min}$ and detection wavelength of $229 \mathrm{~nm}$ was set for analysis. The retention time was within 13 minutes for both the standards.

\subsection{System stability}

The system stability test was assessed by three replicate injections of the standard solutions at a particular concentration. The peak areas were used to evaluate repeatability of the method and its peaks were analyzed for resolution.

The results obtained were represented as parts per billion (ppb) and/or ng equivalent per gram saliva sample.

\subsection{Statistical analysis}

A statistical significant difference was present between the three groups of tobacco chewers, quitters and non-chewers as calculated using Kruskal-Wallis test, one-way analysis of variance (ANOVA) test. Pair-wise comparison of three groups with respect to
NNN \& NNK was done by Mann-Whitney U test. The p-value of less than 0.05 was considered to be statistically significant. ( $p$ value <0.05) Correlation of nitrosamine levels with frequency and duration of tobacco chewing was done with the help of $t$ test.

\section{Results}

In this study the salivary tobacco specific nitrosamines were estimated from 3 groups which were tobacco chewers, tobacco quitters and non-chewers.

In Group I, $77.50 \%$ were male tobacco chewers and $22.50 \%$ were females. Out of 40, 31 were male tobacco chewers and 9 were female tobacco chewers. In Group II (40) i.e. quitters, there were $75 \%$ males (30) and $25 \%$ (10) females. In Group III, $73.33 \%$ were males and $26.67 \%$ were females. All 3 groups showed male predominance. (Table 1).

Table 1: Distribution of Males and Females in Three Study Groups

\begin{tabular}{|c|c|c|c|c|c|c|c|c|}
\hline $\begin{array}{l}\text { Gen- } \\
\text { der }\end{array}$ & $\begin{array}{l}\text { Group } \\
\text { I }\end{array}$ & $\%$ & $\begin{array}{l}\text { Group } \\
\text { II }\end{array}$ & $\%$ & $\begin{array}{l}\text { Group } \\
\text { III }\end{array}$ & $\%$ & $\begin{array}{l}\text { To- } \\
\text { tal }\end{array}$ & $\%$ \\
\hline Male & 31 & $\begin{array}{l}77.5 \\
0\end{array}$ & 30 & 75 & 27 & $\begin{array}{l}67.5 \\
0\end{array}$ & 88 & $\begin{array}{l}73.3 \\
3\end{array}$ \\
\hline $\begin{array}{l}\mathrm{Fe}- \\
\text { male }\end{array}$ & 9 & $\begin{array}{l}22.5 \\
0\end{array}$ & 10 & 25 & 13 & $\begin{array}{l}32.5 \\
0\end{array}$ & 32 & $\begin{array}{l}26.6 \\
7\end{array}$ \\
\hline Total & 40 & 100 & 40 & $\begin{array}{l}10 \\
0\end{array}$ & 40 & 100 & 120 & 100 \\
\hline \multicolumn{9}{|c|}{ Chi-square $=1.1028 \mathrm{P}=0.5751$} \\
\hline
\end{tabular}

The distribution of persons by age groups using Chi-square test was done. (p-value was statistically significant.) In Group I, $12.50 \%$ were in the mean age of $20-29$ years, $30 \%$ were in mean age of 30-39 years, 37.50 were in mean age of 40-49 years, and $20 \%$ were in mean age of $50+$ years. In Group II, $17.50 \%$ were in mean age of $20-29$ years, $17.50 \%$ were in mean age of $30-39$ years, $40 \%$ were in mean age of $40-49$ years and $25 \%$ were in mean age of 50+ years. In Group III, $31.67 \%$ were in mean age of 20-29 years, $19.17 \%$ were in mean age of $30-39$ years, $32.50 \%$ were in mean age of $40-49$ years and $16.67 \%$ were in mean age of $50+$ years. (Table 2).

Table 2: Distribution of Patients in Three Study Groups by Age Groups

\begin{tabular}{|c|c|c|c|c|c|c|c|c|}
\hline Age groups & Group I & $\%$ & Group II & $\%$ & Group III & $\%$ & Total & $\%$ \\
\hline $20-29 y r s$ & 5 & 12.50 & 7 & 17.50 & 26 & 65 & 38 & 31.67 \\
\hline $30-39 y r s$ & 12 & 30 & 7 & 17.50 & 4 & 10 & 23 & 19.17 \\
\hline $40-49 y r s$ & 15 & 37.50 & 16 & 40 & 8 & 20 & 39 & 32.50 \\
\hline $50+y r s$ & 8 & 20 & 10 & 25 & 2 & 5 & 20 & 16.67 \\
\hline Total & 40 & 100 & 40 & 100 & 40 & 100 & 120 & 100 \\
\hline \multicolumn{9}{|c|}{ Chi-square $=33.5946 \mathrm{p}=0.0001 *$} \\
\hline Mean age & 43.43 & & 45.23 & & 32.13 & & 40.26 & \\
\hline SD age & 13.49 & & 14.75 & & 10.93 & & 14.28 & \\
\hline
\end{tabular}

$* \mathrm{p}<0.05$

The prevalence of Gutka and slaked lime consumption was higher in Group I and a consumption of Pan, tobacco was higher in Group II. (Figure 9). 


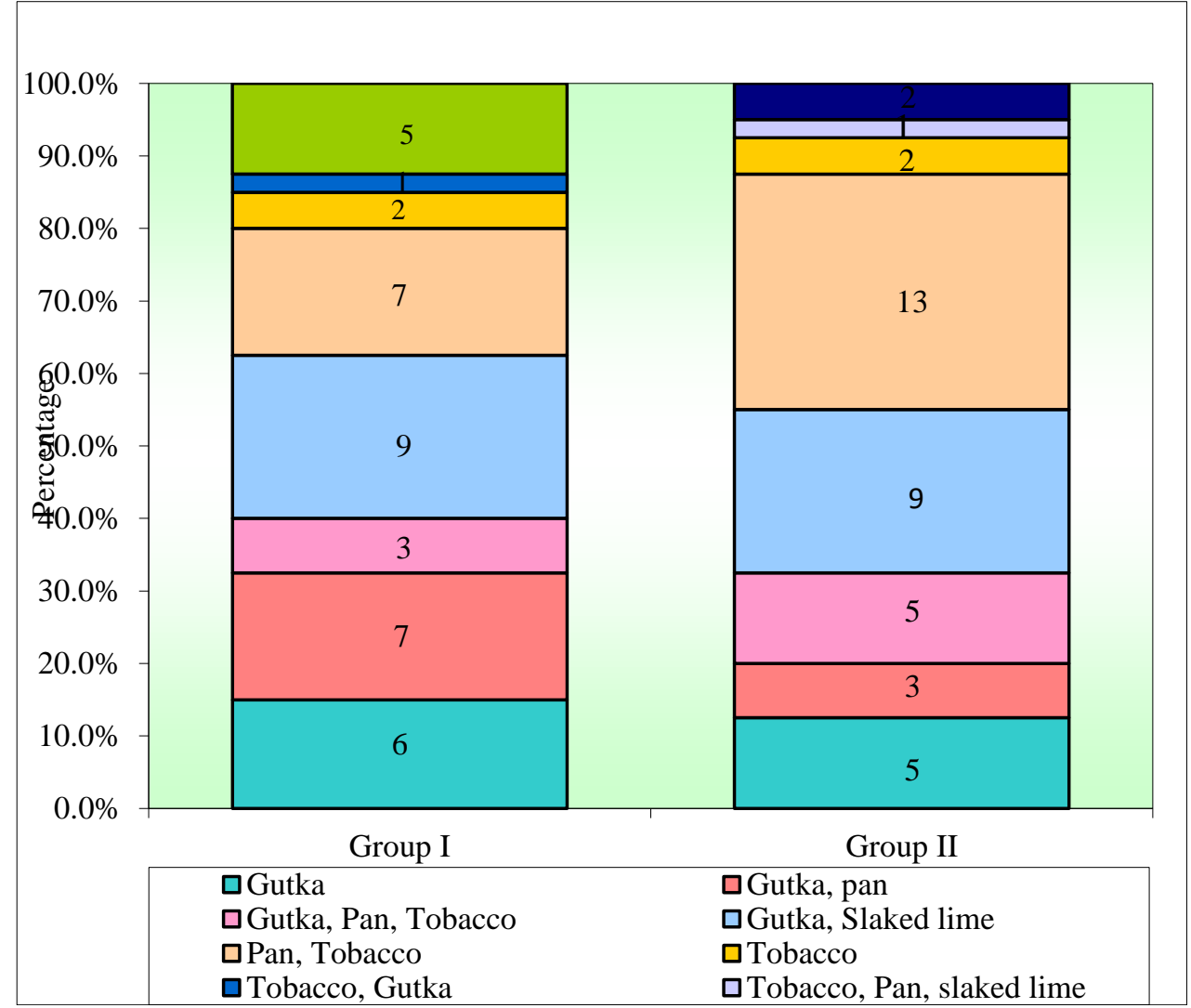

Fig. 9: Comparison of habit of tobacco consumption in groups I and II.

A comparison of duration of tobacco consumption in Groups I and II was done by t test. The Group I depicted a mean of $17.55 \pm 9.90$ years of tobacco consumption and Group II showed a mean of 15.25 years \pm 9.11 years. (p- Value is not significant) (Figure 10).

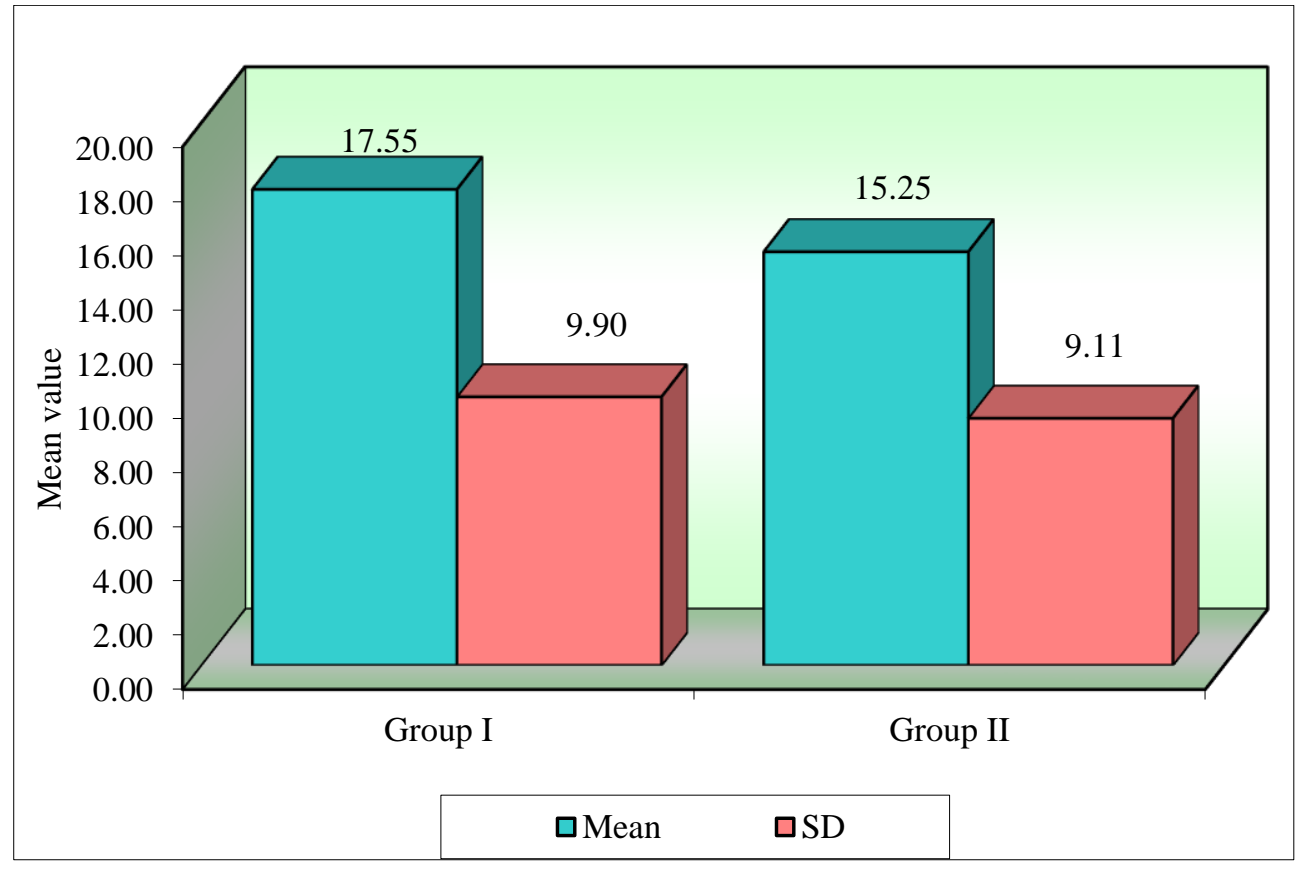

Fig. 10: Comparison of Duration of Tobacco Consumption in Groups I and II.

A mean frequency of tobacco consumption in Groups I and II was estimated by $t$ test. (Figure 11) 


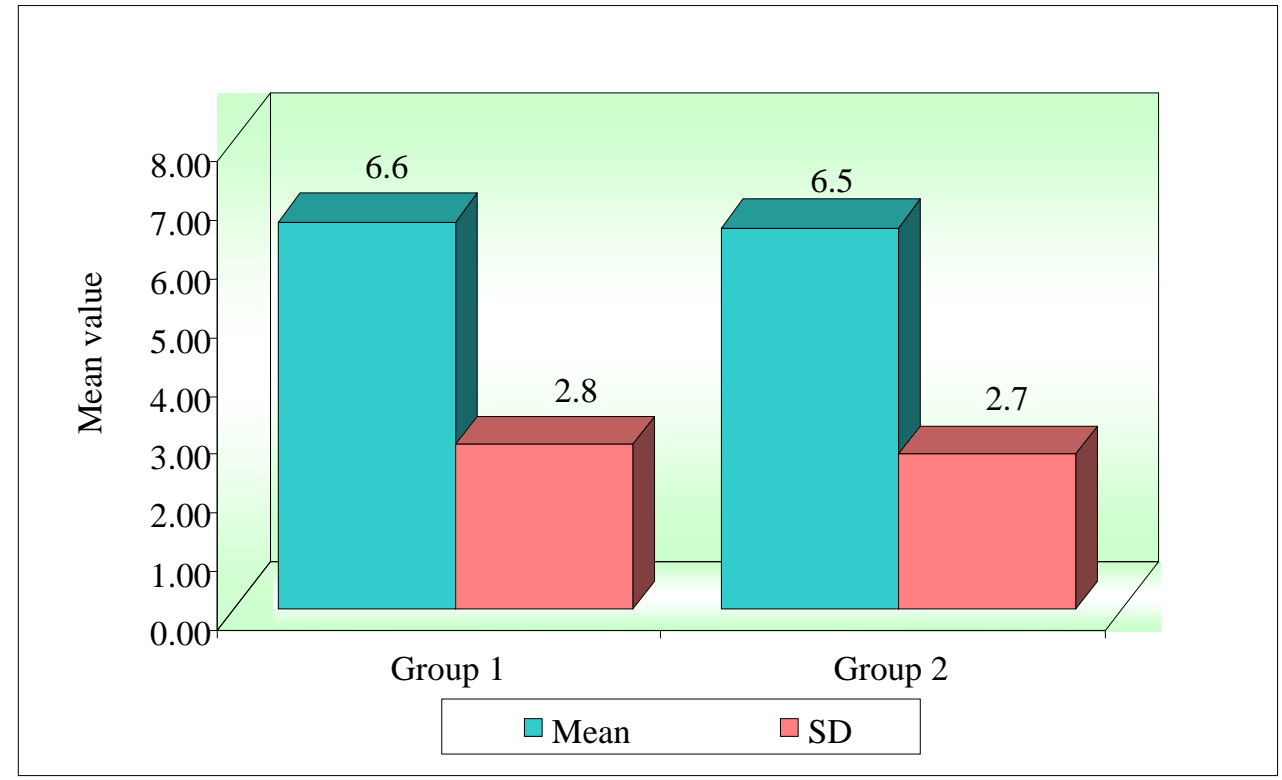

Fig. 11: Comparison of Group I and Group II with Respect to Frequency of Tobacco Consumption.

The frequency of tobacco consumption was $6.6 \pm 2.8$ years in Group I and was $6.5 \pm 2.7$ years in Group II. The range of quitting the tobacco habit was 9.60 years with a mean of $2.48 \pm 1.84$.

(Table 3)

Normality is a measure of concentration equal to gram equivalent weight per litre of solution. NNN and NNK levels in three study groups do not follow a normal distribution in Kolmogorov
Smirnov test. Therefore, the non-parametric tests were applied. (Table 4)

A comparison of NNN values was done in 3 groups with a mean of 651.8 in Group I.

(Figure 12).

Table 3: Summary of Duration of Quitting the Habit in Group II (in Years)

\begin{tabular}{ll}
\hline Summary & Value \\
\hline Minimum & 0.40 \\
Maximum & 10.00 \\
Range & 9.60 \\
Mean & 2.48 \\
SD & 1.84 \\
SE & 0.21 \\
\hline
\end{tabular}

Table 4: Normality of NNN and NNK Levels in Three Study Groups by Kolmogorov Smirnov Test

\begin{tabular}{|c|c|c|c|c|c|c|}
\hline Variables & $\begin{array}{l}\text { Group I } \\
\text { Z-value }\end{array}$ & P-value & $\begin{array}{l}\text { Group II } \\
\text { Z-value }\end{array}$ & P-value & $\begin{array}{l}\text { Group III } \\
\text { Z-value }\end{array}$ & P-value \\
\hline $\mathrm{NNN}$ & 0.9660 & 0.3080 & 1.3620 & $0.0490^{*}$ & 2.3720 & $0.0001^{*}$ \\
\hline NNK & 1.1500 & 0.1420 & 1.4110 & $0.0370 *$ & 2.4010 & $0.0001 *$ \\
\hline
\end{tabular}

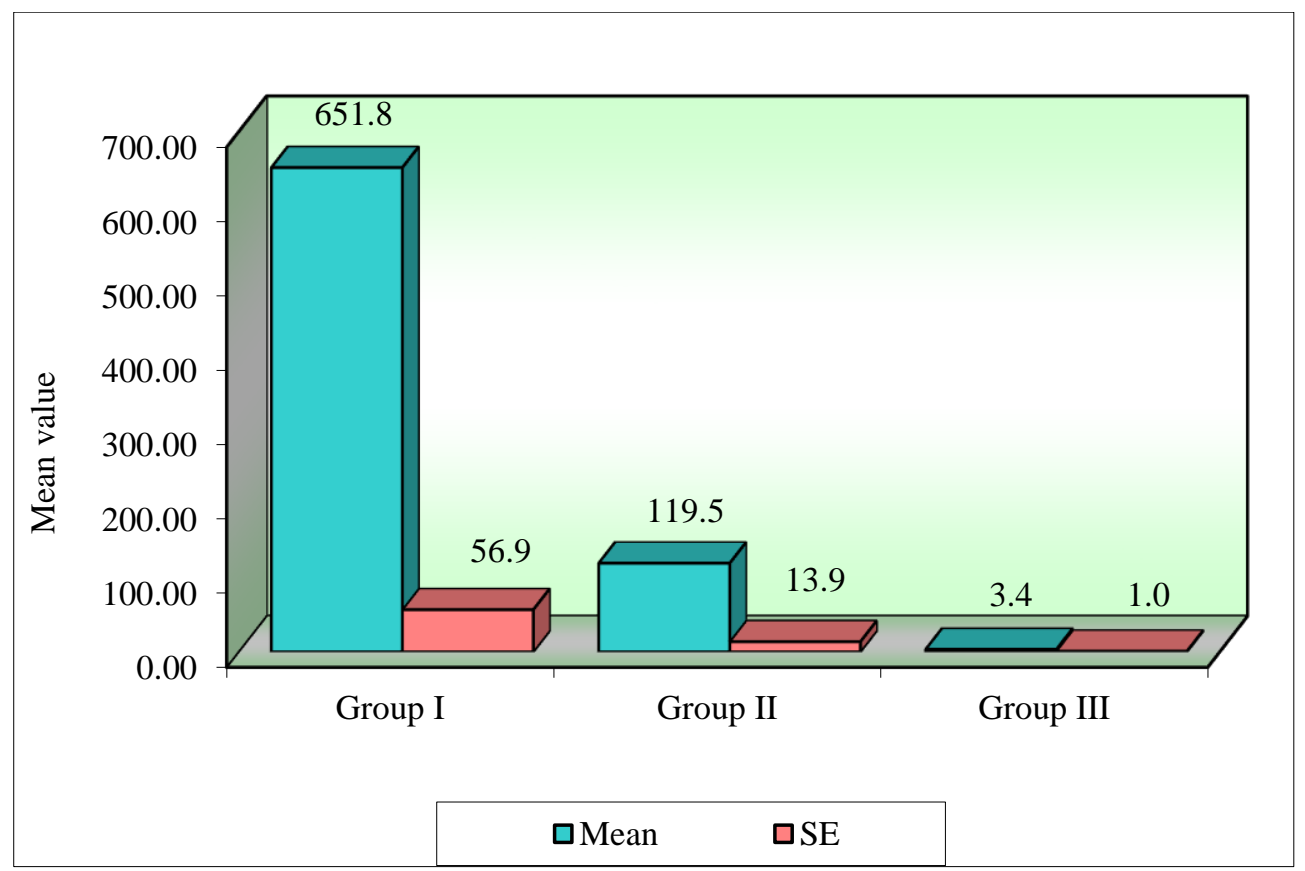

Fig. 12: Comparison of Three Study Groups with NNN Levels. 
A comparison of NNK values was done in 3 groups with a mean of 168.3 in Group I. (Figure 13).

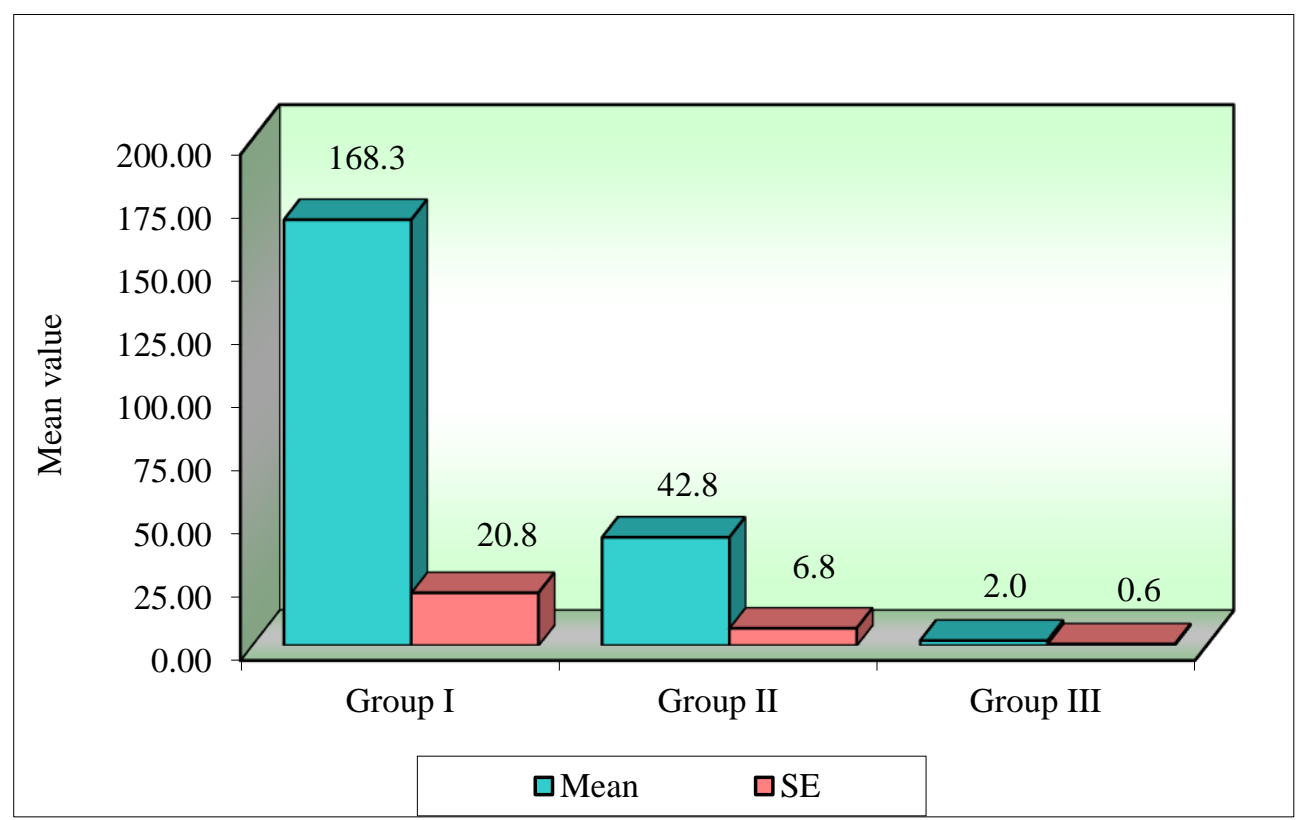

Fig. 13: Comparison of Three Study Groups with NNK Levels.

Table 5: Pair Wise Comparisons of Three Study Groups with NNN Levels by Mann-Whitney U Test

\begin{tabular}{|c|c|c|c|c|c|c|c|}
\hline Groups & Mean & Median & SD & Mean rank & U-value & Z-value & P-value \\
\hline Group I & 651.84 & 589.39 & 359.78 & 58.80 & & & \\
\hline Group II & 119.52 & 95.05 & 87.67 & 22.20 & 68.00 & -7.0437 & $0.0001^{*}$ \\
\hline Group I & 651.84 & 589.39 & 359.78 & 60.50 & & & \\
\hline Group II & 119.52 & 95.05 & 87.67 & 60.50 & & & \\
\hline Group III & 3.44 & 0.00 & 6.55 & 20.50 & 0.00 & -7.6980 & $0.0001^{*}$ \\
\hline
\end{tabular}

Table 6: Pair Wise Comparisons of Three Study Groups with NNK Levels by Mann-Whitney U Test

\begin{tabular}{lllllcc}
\hline 3 & Mean & Median & SD & Mean rank & U-value & Z-value \\
\hline Group I & 168.32 & 131.78 & 131.83 & 52.54 & 318.50 & -4.6332 \\
Group II & 42.78 & 25.12 & 43.19 & 28.46 & $0.0001 *$ & \\
Group I & 168.32 & 131.78 & 131.83 & 60.50 & 0.00 & -7.6980 \\
Group III & 1.98 & 0.00 & 3.68 & 20.50 & $0.0001 *$ \\
Group II & 42.78 & 25.12 & 43.19 & 60.38 & & \\
Group III & 1.98 & 0.00 & 3.68 & 20.63 & $0.0001 *$ & -7.6499 \\
\hline
\end{tabular}

$* \mathrm{p}<0.05$

The pair-wise comparison of 3 study groups with NNN level was done by Mann- Whitney U Test with a statistical significant $p$ value between all three groups. The Group I revealed mean of NNN of $651.84 \pm 359.78$. The Group II depicted a mean of NNN of $119.52 \pm 87.67$. The Group III showed a mean of NNN of 3.44 \pm 6.55 (Table 5).

The inter-group comparison of 3 study groups with NNK scores was done by Mann- Whitney U test. The Group I depicts a mean of NNK of $168.32 \pm 131.83$. The Group II revealed a mean of NNK of $42.78 \pm 43.19$. The Group III revealed a mean of $1.98 \pm$ 3.68 with a statistical significant $p$ value in all 3 groups. (Table 6). The present study showed that there was significant elevation in salivary NNN and NNK levels in tobacco - chewers. The levels of $\mathrm{NNN}$ and NNK values can be detected in the saliva of tobacco quitters.

\section{Discussion}

The use of tobacco is one of the greatest threats to universal health today. Tobacco chewing and smoking are significant risk factors of potentially malignant lesions and cancer of oral cavity in India. (GTAS 2009-2010) Studies have shown that the saliva of tobacco- chewers contains significant amount of TSNA's and that its concentration can vary widely. (Hoffman \& Adams 1981) Assessment of TSNA's and their metabolites in saliva, urine and serum has proven to be extremely useful in estimating human exposure to this carcinogen. (IARC 2004) There is extensive

literature on detection of urinary metabolites of NNK, whereas research on levels of TSNA's in saliva of tobacco chewers and quitters and it's co-relation with cancer and potentially malignant lesions is limited. Nitrosamines are enzymatically converted to unstable electrophilic intermediates (ultimate carcinogens) which can react with nucleophilic centers in cellular macromolecules. (Stepanov et al. 2006) Brunnemann (Brunemann et al. 1986) reported high levels of tobacco-specific nitrosamines in tobacco used in betel quid. Nair (Nair, Bhide et al. 1986) found high levels of tobacco-specific nitrosamines (TSNA's) in Indian population chewing tobacco and creamy snuff. Studies have demonstrated that exposure to substantial amounts of carcinogenic tobacco-specific nitrosamines through use of smokeless tobacco products remains a major health hazard. (Stepanov et al. 2006) Nicotine metabolites have been detected in serum and urine of tobacco users but studies using saliva are sparse. There are no studies comparing presence of TSNA's in tobacco users, those who have quit tobacco use and non-users.

Our study showed a male predominance of tobacco use. Similar findings have been reported in literature. (Sinha 2001, Joshi 2010, GTAS Indonesian report \& Patil 2013) The males and females were distributed to 3 study groups of tobacco chewers and nonchewers by Chi-square test and there was male predominance. 
According to the National Report of Global Adult Tobacco Survey conducted in India, the current prevalence of smokeless tobacco and smoked forms of tobacco use is 25.9 and $27.2 \%$, respectively. (GTAS-2 2016-2017) There are wide varieties of smokeless tobacco products available in India. Majority of these contains tobacco leaves, lime, areca nut, additives, spices, and tannins in varying concentrations. In Karnataka, the use of Gutka and paan is most prevalent. As tobacco is cultivated in Karnataka, it has one of the highest numbers of tobacco consumers in India. (Tobacco Institute of India fact sheets) In this study, two tobacco specific nitrosamines NNN and NNK in saliva were studied in all the 3 groups and the arithmetic means and standard deviations of NNN and NNK levels were calculated. Statistical analysis was performed using Kruskal Wallis test and ANOVA test. The Group I showed a mean NNN level of $651.84 \pm$ $359.78 \mathrm{ppb}$. The Group II showed a mean NNN level of $119.52 \pm$ $87.67 \mathrm{ppb}$. In Group III, the mean NNN level was $3.44 \pm 6.55 \mathrm{ppb}$. The Group I showed a mean NNK level of $168.32 \pm 131.78 \mathrm{ppb}$ The Group II revealed a mean NNK level of $42.78 \pm 43.19 \mathrm{ppb}$ The Group III showed a mean NNK level of $1.98 \pm 3.68 \mathrm{ppb}$. The intergroup comparison revealed a statistically significant

$\mathrm{p}$ value $<0.05$. These NNN and NNK levels were higher than previously reported levels in the saliva of tobacco users; with concentrations of 57-420 ppb of NNN and up to $96 \mathrm{ppb}$ of NNK (Hoffmann \& Adams 1981) and 37-225 ppb of NNN and 0-61 ppb of NNK (Palladino et al. 1986) However, Brunnemann et al. have reported NNN levels of 115-2610 ppb and up to $201 \mathrm{ppb}$ NNK levels in the saliva of snuff dippers. (Brunemann, Hornby 1987) The higher levels of TSNA's found in the present study may be attributed to the greater number of chewers using lime with tobacco. It has been reported that alkaline $\mathrm{pH}$ produced due to lime is conducive due to the leaching out of TSNA's. Also in Karnataka the use of Gutka and pan is most prevalent. Bhide et al. (1986) reported a higher content of total Tobacco specific nitrosamines (TSNA's) in saliva of chewers of tobacco with lime than did chewers of betel quid with tobacco. There are no studies detecting the levels of nitrosamines in persons who have quit the tobacco habit. Tobacco metabolites (cotinine and NNAL) are also detectable in urine of tobacco smokers and quitters. Similarly NNN and tar have also been detected in the urine of smokers. (Maciej et al. 2011) However, N- nitrosamines have also been detected in selected human physiological fluids (blood, urine and gastric contents) and in people who were fed experimental meals containing fish or beef in combination with spinach and vegetable juice. (Lakritz et al. 1982) This was found to contribute to elevated levels of circulating $\mathrm{N}$-nitrosamines in even healthy people who did not use tobacco at all. Circulating and salivary nitrosamines may also be found in passive smokers and individuals who are exposed to environmental smoke. (Stepanov \& Jensen et al. 2006, Hecht et al. 2008, Kavvadias et al. 2009 \& Maciej et al. 2011) The present study revealed that the persons without tobacco habit (Group III) had a mean of NNN of $3.44 \pm 6.55$ and a mean of $1.98 \pm 3.68$ of NNK levels in saliva. Since Nnitrosamines have been detected in healthy individuals, due to dietary and environmental factors, our findings in Group III can be considered normal.

However, this finding has to be correlated with dietary history and history of chronic exposure to passive smoking and exposure to any other environmental smoke. The levels of TSNA's found in the saliva of tobacco chewers in the present study were higher than other studies reported probably because manufacturers in the west have substantially reduced the TSNA's concentrations in finished smokeless tobacco products. Similar measures need to be adopted in developing countries like India.

Saliva is an effective diagnostic tool and carries many advantages over blood; (1) Saliva collection doesn't require highly trained personnel, (2) Saliva collection is non-invasive and painless, (3) the samples are safer to handle, (4) the samples are easier to ship and store, (5) saliva does not clot and requires less manipulation than blood. (Yoshizawa et al. 2013) Salivary secretions contain factors that inhibit the infectivity of HIV, resulting in extremely low or negligible rates of oral transmission.

(Yoshizawa et al.2013) Various salivary biomarkers like lactate dehydrogenase, matrix metalloproteinase, Ki67 and cyclin D1 have been detected in oral cancer. (Hamzany et al. 2015) Recently survivin (Jasiwal \& Goel 2015) and interleukin-6 (Santolia \& Gupta et al. 2016) have been detected in saliva of oral cancer patients, also there are studies detecting the levels of salivary cotinine (Kulza et al. 2012) and serum cotinine (Asha \& Dhanya 2015) in chewers and smokers. The greatest disadvantage of using this method as an aid in tobacco de-addiction is feasibility and availability of resources. The equipments (GCMS; LCMS) required for estimation of salivary TSNA's are currently housed in centres of basic sciences research and engineering institutes. Transporting samples for each visit during the de-addiction counselling program would incur great costs.

Further research should be conducted on salivary nitrosamines in tobacco chewers and quitters in large sample sizes. Detection of salivary nitrosamines could be used as an effective aid to determine abstinence from tobacco during the de-addiction process. Due to the varied advantages of using saliva as a diagnostic tool, many researchers are investigating saliva for detection of wide variety of diseases. It has also shown potential to replace serum/blood/urine and other body fluids in diagnosis of diseases. Future research can also be directed towards developing handheld devices like a lab-on-chip device for chair-side use.

\section{Conclusion}

The present study clearly shows an increase in salivary tobacco specific nitrosamines (TSNA's) NNN and NNK in tobacco-chewers and tobacco-quitters. The levels of these metabolites in patients who have quit tobacco use are lower than the active tobacco- users. The levels of TSNA's found in the saliva of tobacco-chewers in the present study were higher than other studies reported probably because manufacturers in the west have substantially reduced the TSNA's concentrations in finished smokeless tobacco products. Similar measures need to be adopted in developing countries like India. Also people in India use a large amount of slake lime with tobacco which contributed to higher levels of TSNA's. It has been reported that alkaline $\mathrm{pH}$ produced due to lime is conducive to the leaching out of TSNA's. And in Karnataka the use of Gutka and pan is also most prevalent.

Saliva can be used to detect TSNA's and screen for TSNA's during each patient's de-addiction process. At present this is not feasible because of lack of availability of laboratory equipment for routine screening.

\section{Acknowledgement}

I am thankful to Dr. R.K. Joshi Scientist, Regional Medical Research Centre, Belagavi, Dr. Dushyant Reddy, Dr. Shamantak of Jawaharlal Nehru Centre for Advanced Scientific Research, Bangalore (JNCASR) and Dr. Jawali in statistical Analysis.

\section{References}

[1] International Institute for Population Sciences (IIPS), Ministry of Health, and Family Welfare (MoHFW). Global adult tobacco survey (GATS) India 2009-2010. Mumbai and New Delhi: IIPS and MoHFW, Government of India; 2010.

[2] Hoffmann D, Adams JD. Carcinogenic Tobacco-specific NNitrosamines in Snuff and in the Saliva of Snuff Dippers. Cancer Research 1981; 41: 43054308.

[3] Sharma Sugandha, Rajesh K Joshi et al. "Modified UFLC-PDA Method for determination of Nitrosamines" Journal of Analytical Chemistry September 2015, Volume 70, Issue 9 , pp 1153 - 7

[4] IARC. Monographs on the evaluation of carcinogenic risks to humans. Betel- quid and areca nut chewing and some related nitrosamines.vol. 85. Lyon: IARC, 2004. 
[5] Stepanov I, Jensen J, Hatsukami D, Hecht SS. Tobacco-specific nitrosamines in new tobacco products. Nicotine Tob Res. $2006 \mathrm{Apr}$ 8(2):309-13. https://doi.org/10.1080/14622200500490151.

[6] Brunnemann KD, Hornby AP, Stich HF. Tobacco-specific nitrosamines in the saliva of Inuit snuff dippers in the Northwest Territories of Canada. Cancer Lett. 1987 Oct; 37(1):7-16. https://doi.org/10.1016/0304-3835(87)90140-6.

[7] Bhide SV, Nair UJ, Nair J, Spiegelhalder B, Preussmann R. N nitrosamines in the saliva of tobacco chewers or masheri users. Food Chem Toxicol. 1986 Apr; 24(4):293-7. https://doi.org/10.1016/0278-6915(86)90005-0.

[8] Shah N, Sharma PP Role of chewing and smoking habits in the etiology of oral submucous fibrosis (OSF): a case-control study J Ora Pathol Med 1998; 27: 475-9 https://doi.org/10.1111/j.16000714.1998.tb01915.x.

[9] Patil P, Bathi R, Chaudhari S et al. Prevalence of Oral mucosal lesions in dental patients with tobacco smoking, chewing, and mixed habits : A cross-sectional study in South India J. Family Community Med.2013 May- Aug; 20(2) :130-5 https://doi.org/10.4103/2230 8229.114777.

[10] Joshi Urvish, Modi Bhavesh et al. A study on prevalence of chewing form of tobacco and existing quitting patterns in Urban population of Jamnagar, Gujarat Indian J Community Med.2010 Jan;35(1):105-8

[11] Global Adult Tobacco Survey (GTAS) Indonesia report https://doi.org/10.4103/0970-0218.62560.

[12] Sinha DN, Gupta PC Tobacco and areca nut use in male medical students of Patna. National Medical Journal of India. 2001; 14:1768.

[13] Global Adult Tobacco Survey (GTAS-2) India 2016-2017.

[14] Tobacco Institute of India Fact sheets Universal Leaf Tobacco; UN Trade database (2013).

[15] Goniewicz Maciej, Eisner Mark, Ponce Eduardo et al. Comparison of Urine Cotinine and the Tobacco-Specific Nitrosamine Metabolite 4- (Methylnitrosamino)-1-(3-Pyridyl)-1-Butanol (NNAL) and Their Ratio to Discriminate Active From Passive Smoking Nicotine \& Tobacco Research, Volume 13, Number 3 (March 2011) 202-8.

[16] Lakritz L, Gates R.A., Gugger A.M et al. Nitrosamines levels in human blood, urine and gastric aspirate following ingestion of foods containing potential Nitrosamine precursors or preformed $\mathrm{Ni}$ trosamines Fd. Chem Toxic Vol.20, pp 455 to 459, 1982.

[17] Stepanov I, Jensen J, Hatsukami D et al. Tobacco -specific Nitrosamines in new tobacco products Nicotine and Tobacco Research Volume 8, Number 2 (April 2006) 309-13 https://doi.org/10.1080/14622200500490151.

[18] Dominique Kavvadias, Gerhard Scherer, Francis Cheung, Graham Errington et al. Determination of tobacco-specific $N$-nitrosamines in urine of smokers and non-smokers Biomarkers, 2009; 14(8): $547-53$

[19] Hecht SS, Carmella SG, Stepanov I, Jensen J, Anderson A Hatsukami DK. Metabolism of the tobacco-specific carcinogen 4-(methylnitrosamino)-1-(3- pyridyl)-1-butanone to its biomarker total NNAL in smokeless tobacco users. Cancer Epidemiol Biomarkers Prev. 2008 Mar; 17(3):732-5. https://doi.org/10.1158/1055-9965.EPI-07-2843.

[20] Yoshizawa J, Schafer C, Schafer J et al. Salivary Biomarkers: Toward Future Clinical and Diagnostic Utilities Clin Microbiol Rev. 2013 October; 26(4): 781-91.

[21] Hamzany Y, Savulescu D, Iris Borovoi et al. Salivary analysis of Oral cancer biomarkers British Journal of Cancer (2009) 101, 1194 -8 https://doi.org/10.1038/sj.bjc.6605290.

[22] Jaiswal P, Goel A, Mittal R.D Survivin : A molecular biomarker in cancer Indian J Med Res. 2015 Apr; 141(4): 389-97 https://doi.org/10.4103/0971-5916.159250.

[23] Santolia D, Gupta S, Mahajan B et al. Salivary expression of Inerleukin-6 in Oral potentially malignant disorders and Oral squamous cell carcinoma patients International Journal of Current Research Vol.8, Issue 11,pp 42443-42446, November 2016

[24] Kulza M, Wozniak A, Przybylowska SM, Czarnywojtek A, Kurhanska-Flisykowska A, Florek E. Saliva cotinine determination using high-performance liquid chromatography with diode - array detection. Przeglad Lekarski Journal. 2012;69(10):837-40.

[25] V Asha, M Dhanya Immunochromatographic Assessment of salivary cotinine and its correlation with Nicotine dependence in tobacco chewers J Cancer Prev. 2015 Jun; 20(2): 159-63 https://doi.org/10.15430/JCP.2015.20.2.159.

\section{Abbreviations}

TSNA's- Tobacco specific nitrosamines.

ACN - Acetonitrile.

GCMS- Gas chromatography with mass spectrometry.

SLT - Smokeless tobacco.

LCMS- Liquid Chromatography with mass spectrometry.

Gm- Gram.

IARC- International Agency for research on cancer.

NAB- N-nitrosoanabasine.

NAT- N-nitrosoanatabine.

NNK- 4-(methylnitrosamino)-1-(3-pyridyl)-1-butanone.

NNN- N- nitrosonornicotine.

NNAL- 4-(methylnitrosamino) -1-(3-pyridyl)-1-butanol.

NNAL-Gluc - 4-(methylnitrosamino)-1-(3-pyridyl) but-1-yl]-beta-

O-D-glucosiduronic acid.

$\mathrm{NaOH}$-Sodium hydroxide.

$\mathrm{NH}_{4} \mathrm{OAC}-$ Ammonium acetate.

Ngm- Nanogram.

Ppm - Parts per million.

Ppb- Parts per billion.

SD- Standard deviation.

$\mu \mathrm{g}$ - Microgram. 